\title{
COMUNIDADES NEGRAS QUILOMBOLAS: A AGONIA DE UM MOVIMENTO SOCIAL ABANDONADO PELO ESTADO
}

\section{BLACK QUILOMBOLA COMMUNITIES: THE AGONY OF A SOCIAL MOVEMENT ABANDONED BY THE STATE}

\begin{abstract}
Adelmir Fiabani ${ }^{1}$
RESUMO

O impeachment de Dilma Rousseff oportunizou a chegada de Michel Temer ao poder. Apoiado por parlamentares ligados ao latifúndio e defensores do neoliberalismo, Temer aprovou medidas que afeta os remanescentes das comunidades de quilombos. Em 2018, Jair Bolsonaro venceu as eleições e prometeu um 'governo de direita'. Trata-se de política com ataques aos direitos sociais - coletivos e individuais. Bolsonaro e sua equipe não têm intenção de titular as terras quilombolas. São mais de 6.000 comunidades, a maioria não possui o título da terra e muitas correm o risco de desaparecer. A não titulação representa o aniquilamento deste movimento social. Pretende-se discutir a relação do Estado com os quilombolas e perspectivas de titulação na atual conjuntura. Para este fim, analisamos as publicações em periódicos e sites de apoiadores da causa quilombola, documentos produzidos pelos Três Poderes e pesquisas sobre a questão fundiária das referidas comunidades. Concluímos que o Estado se distanciou das comunidades, o Governo Federal não tem interesse na emissão dos títulos e as comunidades vivem tempos de incertezas.
\end{abstract}

Palavras-chave: Remanescentes de quilombo. Terra. Negros. Movimentos sociais.

\section{ABSTRACT}

The impeachment of Dilma Rousseff made it possible for Michel Temer to come to power. Supported by parliamentarians linked to the latifundia and defenders of neoliberalism, Temer approved measures that affect the remnants of quilombo communities. In 2018, Jair Bolsonaro won the elections and promised a 'right-wing government'. It is a policy with attacks on social rights - collective and individual. Bolsonaro and his team have no intention of holding quilombola lands. There are more than 6,000 communities, the majority do not have the title of the land and many are in danger of disappearing. Non-titling represents the annihilation of this social movement. It is intended to discuss the relationship of the State with quilombolas and perspectives of titling in the current situation. To this end, we analyzed publications in periodicals and websites of supporters of the quilombola cause, documents produced by the Três Poderes and research on the land issue of these communities. We conclude that the State has distanced itself from the communities, the Federal Government has no interest in issuing bonds and communities live in times of uncertainty.

Keywords: Quilombo remnants. Earth. Black. Social movements.

\footnotetext{
${ }^{1}$ Atualmente é Professor Associado do Curso de Medicina da Universidade Federal da Fronteira Sul- Campus Passo Fundo- RS. Doutor em História pela Universidade do Vale do Rio dos Sinos. e-mail: adelmirfiabani@hotmail.com
} 


\section{Revista \\ Debates Insubmissos}

\section{INTRODUÇÃO}

Em 1988, com a promulgação da Constituição Federal, as comunidades negras remanescentes de quilombos conquistaram o direito à titulação de suas terras. Um fato inédito na história agrária brasileira. No entanto, desde aquela data, registra-se forte resistência de diversos setores ligados ao latifúndio e representantes do agronegócio ao direito adquirido. Somente em 1991, o Congresso Nacional manifestou-se sobre o artigo 68 do Ato das Disposições Constitucionais Transitórias (ADCT) e a possibilidade de aplicação da Lei. No ano de 1995, ocorreu a primeira titulação de terras em comunidade quilombola. Passados mais de 30 anos da atual Constituição, menos de $10 \%$ das comunidades negras rurais receberam o título de propriedade.

Logo após a promulgação da Constituição Federal, alguns parlamentares, profissionais do Direito, governantes e representantes do agronegócio colocaram em dúvida a legitimidade do Artigo 68 do ADCT. Estabeleceu-se acirrada disputa jurídica, política e ideológica que durou vários anos, retardando a titulação das terras. Mesmo assim, logo após a emissão do primeiro título, outras comunidades quilombolas solicitaram o cumprimento da Lei pelo Estado, dando início ao maior movimento camponês negro do Brasil.

As comunidades negras acreditaram que o Estado iria titular as terras, porém logo perceberam que o sonho estava bem distante da realidade. Todos os presidentes que governaram o país desde a promulgação da Constituição Federal de 1988 pouco fizeram às comunidades negras rurais. Os governos de Michel Temer e Jair Messias Bolsonaro posicionaram-se contra os anseios dos quilombolas, com trocas sucessivas dos órgãos responsáveis pelos trabalhos técnicos, em processo de aniquilamento do movimento social.

\section{NO BRASIL, A TERRA É PARA BRANCO}

A chegada dos europeus à América determinou o fim das terras livres para as populações nativas. Em 1500, os portugueses se apossaram das terras indígenas e, três décadas após, D. João III dividiu sistematicamente o território em latifúndios denominados capitanias. Demarcou-se o solo, que foi distribuído aos capitães-mores, primeiros latifundiários, e, 
estabeleceram-se os direitos e deveres de cada um. Os donatários tinham o poder de expedir forais, que era uma espécie de contrato, pelo qual os sesmeiros e colonos tornavam-se tributários da Coroa ou dos seus donatários ou capitães-mores. Sem dúvida, o germe da propriedade privada acabava de se instalar nas terras livres dos nativos americanos.

\begin{abstract}
Desde cedo, quando se processou a ocupação e colonização do País, institucionalizouse o monopólio da terra. Este prolongou-se durante a vigência do sistema das sesmarias, quando foi feita a distribuição de grandes extensões do território nacional aos senhores portugueses, ao mesmo tempo que eram espoliadas e expulsas as populações arborígenes. [...] A Coroa possuía, doava e tomava as terras; determinava o caráter da produção; determinava o caráter e o sentido do comércio, etc. Determinava o tipo de mão de obra. Legislava sobre as relações de produção e outros aspectos essenciais da vida econômica e social. Determinava a logística militar e as guerras em defesa da colônia subordinada e os ditames dos acordos com Holanda, Espanha e Inglaterra em 1642 - 54 - 61. (VINHAS, 2005, p. 137).
\end{abstract}

O sistema de Capitanias Hereditárias instituiu o latifúndio no Brasil. Para amansar as terras e fazê-las produzir, recorreu-se à escravidão de indígenas e, posteriormente, de africanos. Consequentemente formaram-se duas classes sociais distintas: livres e escravizados. A violência física e psicológica mediou as relações entre escravizadores e escravizados.

As elites agrárias se esquivaram do debate sobre a propriedade da terra. Em 1850, o governo imperial promulgou a primeira lei de terras. Conforme João Pedro Stedile, a Lei 601, de 1850, "normatizou a propriedade privada [...] e regulamentou e consolidou o modelo da grande propriedade rural, que é a base legal, até os dias atuais, para a estrutura injusta da propriedade de terras no Brasil" (STEDILE, 2005, p. 22-23).

A Lei de Terras de 1850 é um exemplo de estratégia articulada pelos grandes proprietários e executada pelo Estado, com propósito de expandir a propriedade privada e impedir os negros/caboclos do acesso a terra. Em 1889, com a proclamação da República, a classe dos proprietários de terra continuou a ditar as regras do jogo e não permitiu a ascensão dos ex-cativos aos patamares superiores da pirâmide social. Em 1930, com a crise do modelo agroexportador, surgiu o modelo de industrialização dependente dos países centrais, desenvolvidos sem rompimento com a oligarquia rural, origem das novas elites dominantes (STEDILE, 2005, p. 28-29). 


\section{Revista \\ Debates Insubmissos}

Todas as iniciativas de acesso a terra pelos camponeses, ou de resistência/defesa dos seus territórios foram rechaçadas pelos representantes do latifúndio, com apoio total do Estado. Como exemplos, citamos o episódio de Canudos, a Guerra do Contestado e o Massacre de Eldorado dos Carajás/Pará e Corumbiara/Rondônia.

Em 1893, em plena República, caboclos, negros, mestiços e outros pobres refugiaramse em Canudos, estado da Bahia. Naquele tempo, o sertão nordestino abrigava cerca de 30 mil homens, mulheres e crianças vítimas do modelo econômico vigente, que buscavam terra a fim de não morrer de fome. Em Canudos, Antônio Conselheiro formou um grupo de resistência e de acolhimento que foi brutalmente perseguido e destruído pelo Estado, em 1987.

Em 1912, por conta da ferrovia São Paulo - Rio Grande do Sul, milhares de sertanejos, caboclos, mestiços foram desalojados de suas terras. Com o final da obra, somaram-se a estes, cerca de oito mil operários que trabalharam na construção da estrada. Liderados por beatos e profetas populares, os sem terra do Contestado reivindicaram terra para todos. O Contestado era o local em disputa na região limítrofe entre Santa Catarina e Paraná. Os coronéis do governo federal, para justificar a matança que estava por vir, "acusaram o monge José Maria de monarquista e, em 1916, dizimaram milhares de pessoas, sem poupar crianças, mulheres e velhos" (FIABANI, 2015, p. 64). Segundo Maurício Vinhas de Queiroz, as tensões sociais "no Contestado se originaram principalmente do desejo de terras, de bem-estar e de segurança do povo 'sertão' [...]" (QUEIROZ, 1966, p. 285-286).

No final da década de 1940 e início da de 1950, no Norte do Estado do Paraná, em Porecatu, registrou-se movimento de resistência pela posse da terra, articulada por camponeses pobres. Da mesma forma que nos demais conflitos, "o uso da força policial e repressiva foi decisiva na derrota e desarticulação do movimento camponês armado. Como resultado da ação, milhares de camponeses foram deserdados e expulsos de suas terras e deslocados para outras regiões do Estado" (PRIORI, 2009, p. 1).

Em 1950, na região de Trombas e Formoso, norte do estado de Goiás, tivemos outro conflito pela posse da terra. Segundo o geógrafo Leon Martins Carriconde Azevedo (2014, p. 68-89), 


\section{Revista \\ Debates Insubmissos}

Os posseiros que vieram a se instalar em Trombas e Formoso eram camponeses pobres e migrantes advindos de outras expulsões de terras. Eram homens, mulheres e crianças dos sertões da Bahia, do Ceará, do interior do Maranhão, do Piauí, e também de diversos pontos de Goiás, todos eles vinham fugidos da seca, da miséria e da exploração, vítimas do latifúndio.

Em 1964, os camponeses de Trombas e Formoso foram atacados pelas forças armadas. A resistência campesina foi arrasada, seguida de prisões, torturas e perseguições. Alguns líderes desapareceram misteriosamente e ainda são procurados pelos familiares.

A concentração de terras foi um processo contínuo no século XX, como consequência aumentou consideravelmente o número de camponeses sem terra. Segundo o Anuário Estatístico (1960, p. 65), em 1960,

33 mil proprietários concentravam em seus estabelecimentos 126 milhões de hectares de terra. Ao mesmo tempo, mais de 10 milhões de trabalhadores não possuíam qualquer nesga de chão e 1,5 milhão de lavradores pobres que tenham menos de 10 hectares dispunham de apenas 6 milhões de hectares de terra.

Ainda na década de 1960, João Goulart acenou com proposta de reforma agrária, fato que irritou os setores conservadores do Brasil. Em 1964, as elites brasileiras protagonizaram o golpe militar, que representou o mais duro ataque às liberdades individuais e permitiu a maior acumulação de terras nas mãos de poucos proprietários. De 1964 a 1985 a nação brasileira viveu tempos sombrios. O modelo econômico adotado pelos militares caracterizou-se pela exclusão, determinando forte êxodo rural. As periferias dos grandes centros urbanos cresceram desproporcionalmente, como consequência tivemos aumento da fome, da violência e da miséria.

Com o fim do regime militar, fez-se necessária uma nova Constituição. Em 1988 foi aprovada a Carta Magna com uma novidade relacionada às comunidades negras rurais - o Artigo 68 do Ato das Disposições Constitucionais Transitórias. Por este dispositivo constitucional as comunidades remanescentes de quilombos foram reconhecidas como proprietárias das terras por elas ocupadas. Cem anos após a Abolição, o Estado reconhece o direito da população negra brasileira à propriedade da terra.

No momento em que as primeiras comunidades negras solicitaram ao Estado a regularização fundiária com base no Artigo 68 do ADCT, houve divergências interpretativas 
no Congresso Nacional e em alguns setores dos poderes Executivo e Judiciário. Seria o referido artigo autoaplicável ou não? Alguns parlamentares insistiram em dizer que o mesmo deveria ser regulamentado, pois havia dúvidas sobre 'quem eram os remanescentes de quilombos', dando a entender que nem todas as comunidades negras teriam direito à titulação de suas terras.

Ao perceber que poucas comunidades seriam atendidas, caso fosse mantido o sentido histórico do quilombo colonial/imperial - refúgio de cativo fugido -, ativistas, lideranças das comunidades negras, membros do movimento negro organizado, antropólogos, sociólogos, historiadores, profissionais do Direito e outros decidiram pela ressignificação do termo. Fez-se o 'alargamento' do significado da palavra quilombo. Este passou a representar também comunidade negra contemporânea com história ligada à escravidão, formada antes ou depois da data da Abolição.

Em 1994, a Associação Brasileira de Antropologia (ABA), após vários debates, definiu que os remanescentes de quilombos não seriam somente os "grupos isolados ou de uma população estritamente homogênea" ou aqueles constituídos a partir de uma "referência histórica comum, construída a partir de vivências e valores partilhados", mas os "grupos étnicos conceitualmente definidos pela Antropologia como um tipo organizacional que confere pertencimento através de normas e meios para indicar afiliação ou exclusão" (OLIVEIRA, 1996, p. 11-27).

O quilombo antigo foi consagrado pela historiografia como fenômeno histórico/sociológico do trabalhador escravizado que rompeu com a escravidão e formou uma comunidade livre/autônoma dentro da ordem escravista, verdadeiro enclave de liberdade no seio do cativeiro. O fenômeno quilombola acaba com a Abolição da escravidão, visto que não era mais necessário fugir para ser livre e ter autonomia sobre a forma de trabalho. $\mathrm{O}$ que permaneceu foram as comunidades negras. Ao ressignificar o quilombo, as comunidades que não se constituíram deste fenômeno também passaram a ser designadas quilombolas (Cf. FIABANI, 2012).

O quilombo ressignificado tem como pilar de sustentação a resistência. No passado, os quilombolas resistiram à escravidão; no presente, as comunidades negras resistem à 
expropriação e ao aniquilamento religioso/cultural. Não há como negar que houve resistência em ambas as épocas, mas o elemento principal que difere um fenômeno do outro é a autonomia sobre a força de trabalho que o cativo conquistou com a Abolição. Se antes de 1888 era necessário fugir e formar quilombos para ser livre, em tese, após a Abolição todos ficaram livres e puderam usufruir da força de trabalho. Juridicamente, o ex-cativo não era mais propriedade de ninguém, no entanto ficou refém do sistema, em condições análogas às da escravidão.

A ressignificação do termo quilombo interferiu na essência do fenômeno histórico/sociológico protagonizado pelos cativos conscientes da condição que lhes fora imposta. Também modificou a história das comunidades que não nasceram deste fenômeno. No entanto, o resultado deste processo foi mais positivo quando viabilizou a inclusão de mais comunidades negras no contexto da regularização fundiária.

Outra dúvida surgida nos primeiros anos de vigência do Artigo 68 do ADCT, dizia respeito a quem cabia a responsabilidade pela titulação. Mesmo a Lei determinando o 'Estado' como encarregado pela titulação, houve dúvidas se os institutos de terras estaduais e municipais poderiam ou não regulamentar as áreas 'quilombolas'. Este fato retardou por algum tempo a demanda dos quilombolas.

\section{FERNANDO HENRIQUE CARDOSO TRAIU OS QUILOMBOLAS}

O número de comunidades negras que recorreram ao Estado para regularizar suas terras cresceu significativamente na década posterior à promulgação da Constituição Federal, consequência da ressignificação do termo quilombo e do Decreto 4.887, de 2003, que será abordado posteriormente.

Com o elevado número de pedidos protocolados, o Presidente Fernando Henrique Cardoso percebeu que não poderia atender todas as comunidades negras. Em 1999, decidiu retirar o Instituto Nacional de Colonização e Reforma Agrária (INCRA) do processo e transferiu para a Fundação Cultural Palmares (FCP) a responsabilidade, mesmo sabendo que a autarquia não teria condições para desempenhar esta função (BRASIL, 1999). 


\section{Revista \\ Debates Insubmissos}

O Presidente Fernando Henrique Cardoso também determinou que fossem tituladas somente comunidades remanescentes dos antigos quilombos, mediante a comprovação de residência no local, com data anterior a 1888 (BRASIL, 1999). Através desta norma, FHC inviabilizou o processo de titulação, pois a maioria das comunidades não descende de antigos quilombos e seria muito raro encontrar uma comunidade que permaneceu no local por mais de cem anos. Durante a escravidão no Brasil, os mocambeiros foram constantemente atacados e tiveram que fugir para salvar as próprias vidas. Também houve deslocamentos de quilombolas por outros motivos, como o esgotamento do solo.

Desde que entrou em vigor a Constituição de 1988 e, consequentemente, o Artigo 68 do ADCT, as ações concentraram-se mais nas discussões conceituais do que na esfera das titulações. Durante o governo FHC poucas comunidades foram tituladas, também algumas delas receberam a documentação sem valor, pois foram emitidos títulos em terras de terceiros. ${ }^{2}$ As comunidades negras sentiram-se traídas por FHC, pois o sociólogo muitas vezes defendeu os trabalhadores durante sua vida acadêmica e também como parlamentar, mas que se tornara um aliado das elites agrárias ao eleger-se presidente da República.

Algumas comunidades negras foram tituladas mesmo antes da regulamentação do Artigo 68 do ADCT, sobretudo, no Maranhão e Pará, onde o movimento estava organizado antes mesmo da atual Constituição entrar em vigor. A primeira comunidade titulada foi Boa Vista, no município de Oriximiná, em 1995.

Somente em 2003, com a posse do Presidente Luiz Inácio Lula da Silva, as comunidades negras conquistaram o direito de autoidentificarem-se como remanescentes de quilombos, ou seja, por meio do decreto 4.887 , as comunidades negras não necessitavam mais de um "atestado" vindo de fora para dizerem-se quilombolas.

A eleição de Lula, um presidente oriundo das classes populares, com brilhante participação nas greves dos metalúrgicos, elevou o ânimo das comunidades, que passaram a sonhar com a titulação das terras. No entanto, o número de comunidades tituladas pelo

\footnotetext{
${ }^{2}$ Oito territórios titulados pela FCP sem a retirada ou indenização dos ocupantes não quilombolas (proprietários e/ou posseiros). In: BRASIL. INCRA. Quilombolas. Brasília. 2015.
} 
Presidente ficou aquém da expectativa do movimento quilombola. Cabe evidenciar que o movimento quilombola reconheceu que os últimos dois presidentes - Lula e Dilma - não foram efetivos, visto que andavam de 'mãos dadas' com os representantes do agronegócio, setor majoritariamente contrário aos interesses das comunidades negras.

\section{INIMIGOS NO GOVERNO}

A eleição da Presidenta Dilma Vana Rousseff foi possível mediante acordos com partidos ideologicamente contrários aos interesses do Partido dos Trabalhadores. Esse fato resultou em dificuldades para formar a equipe de governo, pois havia pessoas indicadas pelos partidos aliados com posições ideológicas diferentes.

Na Câmara dos Deputados, centenas de parlamentares seguiam as ordens de Eduardo Cunha, advogado, religioso, que responde a vários processos sobre corrupção em órgãos que comandou. Eleito presidente, colocou em votação pautas que alterariam a legislação trabalhista e previdencial, com prejuízo ao trabalhador e benefícios aos empresários do grande capital. As famosas pautas 'bomba' inviabilizaram o governo Dilma. A grande mídia, a Federação das Indústrias do Estado de São Paulo (FIESP) e alguns institutos de pesquisa trataram de 'isolar' a Presidenta fazendo a popularidade baixar a níveis ridículos.

Em 17 de março de 2016, em sessão transmitida ao vivo para o Brasil e o mundo, 369 deputados, comandados por Eduardo Cunha, protagonizaram o maior ataque à democracia nos últimos 20 anos. Em 31 de agosto do mesmo ano, o Senado Federal julgou a Presidenta Dilma, acusada de crime de responsabilidade fiscal, que perdeu o poder, assumindo o Vice-Presidente Michel Temer.

Michel Temer prometeu 'tirar' o país da crise econômica com medidas severas, sobretudo, combater a corrupção e aprovar soluções desenvolvimentistas. Na verdade, o Presidente não cumpriu o que prometeu. Temer cercou-se de políticos conservadores e passou a governar a favor do grande capital nacional e estrangeiro, em detrimento da classe trabalhadora. Os avanços conquistados pelos trabalhadores, quilombolas, indígenas e minorias passaram a ser questionados. 
Os principais auxiliares de Temer eram pessoas que representavam o pensamento conservador da elite brasileira. Temer formou um quadro administrativo, com ministros pinçados no Congresso, não por qualidades administrativas, mas por se identificar com o agronegócio, sistema financeiro e grande capital. Os movimentos sociais, negros, indígenas, quilombolas, trabalhadores, pobres, homossexuais e minorias não estavam representados.

Para a Casa Civil, Temer indicou Eliseu Padilha com a missão de 'costurar acordos' entre os parlamentares de diferentes partidos, a fim de implementar as medidas duras contra os 'privilégios' da classe trabalhadora. Na verdade, o discurso de 'terra arrasada' serviu para 'legitimar' a privatização das estatais que pertencem à nação brasileira. Já no Ministério da Agricultura, Pecuária e Abastecimento assumiu o senador Blairo Maggi, latifundiário com propriedades no Mato Grosso, genuíno representante do agronegócio.

No Ministério do Desenvolvimento Social e Agrário ocupa pasta o deputado eleito pelo Rio Grande do Sul, Osmar Terra. Também homem de extrema confiança do Presidente e de Eliseu Padilha. O referido Ministro insinuou cortes nos programas sociais, como o programa Bolsa Família. Como deputado federal, assumiu algumas posturas reacionárias recentemente, como a elaboração do projeto de Lei que institui a internação compulsória dos usuários de drogas ilícitas, em tramitação no Senado. Ele também assinou, junto ao deputado Jair Bolsonaro, um projeto que extingue o regime semiaberto nas prisões.

No dia 24 de abril de 2016, Alceu Moreira, deputado do Movimento Democrático Brasileiro (MDB), um dos articuladores do impeachment de Dilma, manifestou-se contrário aos auxílios para os aposentados, para os beneficiários do Programa Bolsa Família e outros. O deputado federal pronunciou: "Aviso aos navegantes. O tempo da 'vagabundização' remunerada acabou, não adianta gritar é que dói, mas vagabundo remunerado não receberá." (SOARES, 2016, s.p).

\section{CERCO AOS QUILOMBOLAS}

Em 12 de maio de 2016, menos de um mês após a tomada do poder, através da Medida Provisória 726, o presidente Michel Temer delegou a regularização das terras quilombolas ao 
Ministério da Educação e Cultura (MEC) (BRASIL, 2016). Este ato foi recheado de intenções duvidosas, pois o MEC teria como função a "delimitação das terras dos remanescentes das comunidades dos quilombos, bem como determinação de suas demarcações, que serão homologadas mediante decreto." O MEC estava sob o comando do Ministro Mendonça Filho, filiado ao Partido Democrata, que é contrário às pretensões dos quilombolas.

O Partido Democrata (DEM) é responsável pela Ação Direta de Inconstitucionalidade 3239 (STF, 2016), que tramita no Supremo Tribunal Federal opondo-se ao Decreto 4.887/2003, ou seja, grave ameaça aos direitos das comunidades negras brasileiras. Sem contar, que o DEM sempre defendeu a propriedade privada, o latifúndio, combateu o Movimento dos Trabalhadores Sem Terra e outros movimentos sociais.

Temer repetiu a política do ex-presidente Fernando Henrique Cardoso, que, em 1999, retirou do INCRA a incumbência de titular as terras e passou para a Fundação Cultural Palmares, decisão política maléfica às comunidades remanescentes de quilombos. Na época, a decisão de FHC tencionava interromper ou atrasar o andamento dos processos de regularização das terras quilombolas. As consequências do ato do ex-presidente ainda são sentidas pelas comunidades, visto que alguns títulos emitidos pela FCP continuam na ilegalidade.

Michel Temer passou a questão quilombola para o Ministério da Educação e Cultura. Este ministério não foi criado para cuidar da questão fundiária, também não tem experiência nesta atividade e não disponibiliza de técnicos para fazer o trabalho de campo. Em outras palavras, o Governo Federal reconhece o direito das comunidades negras, mas não quer efetivar as titulações, transferindo a incumbência para quem não sabe fazer.

A decisão de Temer repercutiu de forma tão negativa, que o mesmo revogou o ato anterior e a Medida Provisória no dia 20 de maio de 2016, devolvendo a tarefa para o INCRA, que, por sua vez, foi vinculado ao novo Ministério do Desenvolvimento Social e Agrário. Finalmente, em 27 de maio de 2016, por meio do Decreto 8.780, Temer passou o INCRA para a tutela da Casa Civil.

A Casa Civil ficou sob responsabilidade de Eliseu Padilha, um dos políticos com maior influência sobre Michel Temer. Ao retirar a incumbência do INCRA e transferir este órgão para 
o MEC, posteriormente, para Casa Civil, demonstra que a questão fundiária das comunidades negras passou do campo do direito/agrário para o campo das políticas/intenções de governo.

Em 30 de maio de 2016, notícia publicada no site da Comissão Pró-Índio de São Paulo, mostrou inconformidade do Movimento dos Trabalhadores Rurais Sem Terra (MST) com o ato governamental acima citado. Segundo Alexandre Conceição, "transferir o INCRA para a Casa Civil é como colocar raposa para cuidar do galinheiro". De acordo com Conceição, o chefe da Casa Civil, Eliseu Padilha, "é vinculado aos ruralistas". Permitir a política do campo e da Reforma Agrária sob sua administração "é inviabilizar qualquer avanço". (CPISP, 2016, s.p).

\section{OS VELHOS INIMIGOS DE SEMPRE}

Em novembro de 2015, parlamentares da bancada ruralista do Congresso conseguiu criar e controlar uma Comissão Parlamentar de Inquérito (CPI) da Fundação Nacional do Índio (FUNAI), com o intuito de investigar também o Instituto Nacional de Colonização e Reforma Agrária (INCRA). A cúpula mandante da referida Comissão apoiou a Proposta de Emenda à Constituição $n^{0} 215$ (PEC 215), que inclui o Congresso Nacional na demarcação de terras indígenas e quilombolas. "Juntos, esses deputados receberam mais de $\mathrm{R} \$ 9$ milhões de empresas e empresários do setor agropecuário nas eleições de 2014" (MEDEIROS, 2015, s.p).

Esta CPI não passou de um instrumento de empoderamento das elites mandantes contra os movimentos sociais quilombola e indígena. As irregularidades encontradas transformaramse em motivo para desqualificação dos segmentos e motivos para atacá-los publicamente. No Brasil, latifundiários, grandes empresários, espertalhões não encontram dificuldades para regularizar terras, muitas vezes, obtidas de forma ilegal.

\section{NOVOS PARÂMETROS PARA AS TITULAÇÕES DAS TERRAS QUILOMBOLAS}

O Presidente Michel Temer, sabedor do teor da Ação Direta de Inconstitucionalidade 3239, que, na época, estava sendo votada no Supremo Tribunal Federal (STF), decretou que 
nenhuma comunidade seria titulada antes do fim do julgamento. Assim os processos foram suspensos e sem prazo para ser retomados. A ação foi apresentada pelo partido Democrata (DEM), com o objetivo de derrubar um decreto de 2003 do ex-presidente Luiz Inácio Lula da Silva. O decreto regulamentou o trâmite de identificação e demarcação de terras ocupadas por remanescentes das comunidades quilombolas.

A votação iniciou em 2012, com o voto do Ministro Cézar Peluso, que admitiu a incostitucionalidade do decreto. Em 2015, a Ministra Rosa Weber, votou favorável aos quilombolas. Faltavam mais nove ministros se pronunciarem. Em 8 de fevereiro de 2018, por maioria de votos, o Supremo Tribunal Federal declarou a validade do Decreto 4.887/2003, garantindo, com isso, a titulação das terras ocupadas por remanescentes das comunidades quilombolas (STF, 2018).

A decisão de Temer inviabilizou por um tempo todas as ações do Estado em relação às comunidades remanescentes de quilombos. Nesse sentido, o presidente atendeu a demanda da bancada ruralista, que é contrária aos direitos quilombolas. Temer também editou a PEC 55, que atingiu em cheio as pretensões dos quilombolas. A dotação orçamentária do INCRA foi reduzida em 97\% se comparados os valores de 2018 aos de 2013 (Cf. MORAES, 2020, s.p).

\section{JAIR BOLSONARO E O MOVIMENTO QUILOMBOLA}

Ao tomar posse, Jair Bolsonaro editou a Medida Provisória 870, atribuindo a identificação, reconhecimento, delimitação e titulação das terras ocupadas pelos remanescentes de quilombos ao Ministério da Agricultura, Pecuária e Abastecimento, comandada por representantes do latifúndio e do agronegócio (BRASIL, 2019). Nos primeiros 100 dias do seu governo nenhuma comunidade foi titulada.

Conforme o documentário "Racismo e violência contra Quilombolas no Brasil", existem 6 mil comunidades espalhadas pelo território nacional, sendo apenas 3.200 reconhecidas pela FCP (CONAQ, 2018). De acordo com dados do INCRA, foram emitidos 232 títulos, regularizando 754.515,6476 hectares em benefício de 153 territórios, 296 comunidades e 15.804 famílias quilombolas (INCRA, 2020). 


\section{Revista \\ Debates Insubmissos}

São mais de 1600 processos parados no INCRA. A inércia total afeta milhares de famílias que não conseguem planejar suas ações devido à falta do documento legitimador da propriedade. Segundo Denildo de Moraes, coordenador da Coordenação Nacional de Articulação das Comunidades Negras Rurais Quilombolas (Conaq),

É um governo que nós não elegemos. É um governo racista e preconceituoso. É um governo que, antes mesmo de se eleger, já havia colocado dentro da sua plataforma política falas contra os direitos quilombolas, contra os direitos dos povos e comunidades tradicionais e indígenas (MORAES, 2019, s.p)

O movimento das comunidades quilombolas percebeu que o Estado não tem interesse na titulação das terras, pois este governo demonstra simpatia com o agronegócio. São milhares de hectares que estão em jogo. A titulação das terras quilombolas retira este bem do mercado de terras e afeta os interesses dos fazendeiros, especuladores e do agronegócio.

\section{CONCLUSÃO}

A não titulação das terras quilombolas determina a aniquilação do movimento. Ou seja, o Artigo 68 do ADCT é bem claro: garante o direito das comunidades terem suas terras tituladas e define o Estado como responsável pela emissão dos títulos. Quando o Estado posterga a titulação, as comunidades permanecem desprotegidas e expostas às ações dos grileiros, espertalhões, fazendeiros e agronegócio, pois suas propriedades são cobiçadas por estes segmentos.

As comunidades negras rurais dependem da terra para sobreviver. Sem o título, algumas políticas públicas deixam de ser acessadas, inviabilizando o desenvolvimento econômico e social. Sem o fomento do Estado, a produção agrícola/pecuária/artesanal torna-se praticamente inviável, como consequência, as pessoas em condições de trabalho deixam as comunidades e buscam empregos onde há oferta.

Registra-se 'encolhimento' em várias comunidades do Brasil, consequência do êxodo rural. No Rio Grande do Sul, algumas comunidades são compostas majoritariamente por crianças e idosos, fato que se verifica em outros estados do Brasil, pois jovens e adultos 


\section{Revista \\ Debates Insubmissos}

procuram os centros urbanos, a fim de trabalhar e continuar os estudos. Somente com a titulação das terras e implantação de ações desenvolvimentistas sérias, evitar-se-á o êxodo rural.

Também aumentaram os atos violentos contra as comunidades. A morosidade do Estado em solucionar a questão fundiária quilombola acaba empoderando os agentes especuladores de terras, fato que, muitas vezes, resulta em conflitos com os moradores das comunidades. O número de assassinatos de 2016 para 2017 cresceu em aproximadamente $350 \%$, ou seja, não se trata de invasão de território, destruição das plantações, impedimento do direito de ir e vir, mas de vidas que foram interrompidas.

Os presidentes Temer e Bolsonaro pouco ou nada fizeram pelas comunidades negras. Trabalharam no sentido de paralisar o processo de titulação. Se não bastasse o abandono por parte do Estado, frequentemente, lideranças políticas constrangem publicamente os quilombolas, como fez o atual presidente em evento no Clube Hebraica no Rio de Janeiro. Jair Bolsonaro afirmou que visitou um quilombo e encontrou a pessoa mais leve pesando "sete arrobas" (SILVA, 2018, p. 52). Esta declaração ofendeu profundamente o povo negro, pois foram comparados a animais.

A ascensão dos representantes do agronegócio e bancada ruralista ao poder representa a interrupção de várias conquistas do movimento negro e dos camponeses pobres. Não seria diferente com o movimento das comunidades quilombolas. Os partidos políticos e seus representantes que contestaram o dispositivo constitucional logo após a promulgação da Constituição Federal são os mesmos que governam o país hoje. Não restam dúvidas que o pleito quilombola não será atendido.

Com a dissolução das comunidades negras rurais, padece também a cultura, a história, a religiosidade e as tradições. Nas referidas comunidades há pessoas que guardam os saberes dos antepassados e os praticam de forma que as gerações mais jovens possam aprender e ensinar aos seus descendentes. São lembranças do passado, rituais religiosos, fórmulas de remédios naturais, conhecimento sobre a natureza que se perderão. Basta pouco tempo de convívio com os costumes urbanos, para que os jovens das comunidades abandonem suas tradições em nome da 'modernidade'. 


\section{REFERÊNCIAS}

AZEVEDO, Leon Martins Carriconde. A revolta camponesa de Trombas e Formoso e a contribuição da teoria anarquista. Em Debate: Rev. Dig., Florianópolis, n. 11, p. 68-89, janjun, 2014.

BRASIL. Anuário Estatístico do Brasil. Brasília. 1960.

BRASIL. Casa Civil. Medida Provisória 726. Brasília. 12 de maio de 2016.

BRASIL. Casa Civil. Medida Provisória n. 870. Brasília. 2019.

BRASIL. Casa Civil. Proposta de Emenda à Constituição n. 55, de 2016. Disponível em: https://www25.senado.leg.br/web/atividade/materias/-/materia/127337. Acessado em 06 de março de 2020.

BRASIL. INCRA. Quilombolas. Brasília. 2020.

BRASIL. Ministério da Cultura. Portaria nº 447, de 2 de dezembro de 1999.

CONAQ (Org.). Racismo e violência contra quilombolas no Brasil. Curitiba: Terra de Direitos, 2018.

CPISP. Mais uma mudança: titulação de terras quilombolas vai para a Casa Civil.

Disponível em: http://cpisp.org.br/mais-uma-mudanca-titulacao-de-terras-quilombolas-vaipara-a-casa-civil/. Acessado em 31 de maio de 2016.

FIABANI, Adelmir. Mato, palhoça e pilão: o quilombo, da escravidão às comunidades remanescentes. [1532-2004]. 2. ed. São Paulo: Expressão Popular, 2012.

FIABANI, Adelmir. Os novos quilombos: luta pela terra e afirmação étnica no Brasil [1988-2008]. Palmas: Nagô Editora, 2015.

INCRA. Oito territórios titulados pela FCP sem a retirada ou indenização dos ocupantes não quilombolas (proprietários e/ou posseiros). In: BRASIL. INCRA. Quilombolas. Brasília. 2015. 
MEDEIROS, Étore. Devassa ruralista na Funai e no Incra. Disponível em: https://apublica.org/2015/11/truco-devassa-ruralista-na-funai-e-no-incra/. Acessado em 26 de novembro de 2015 .

MORAES, Denildo de. Como os quilombolas têm avaliado o governo Bolsonaro?

Disponível em: https://www.almapreta.com/editorias/realidade/como-os-quilombolas-temavaliado-o-governo-bolsonaro. Acesso em 02 de março de 2020.

OLIVEIRA, João Pacheco de et al. Documento do Grupo de Trabalho sobre Comunidades Negras Rurais. 1994. In: Boletim Informativo NUER, n. 1, Regulamentação de Terras de Negros no Brasil, Florianópolis: UFSC, 1996.

PRIORI, Ângelo. A revolta camponesa de Porecatu. ANPUH - XXV SIMPÓSIO

NACIONAL DE HISTÓRIA - Fortaleza, 2009.

QUEIROZ, Maurício Vinhas de. Messianismo e Conflito Social (A Guerra Sertaneja do Contestado: 1912-1916). Rio de Janeiro: Ed. Civilização Brasileira, 1966.

SILVA, Halda Simões. Professoras quilombolas no agreste pernambucano: desafios e tensões de uma identidade em construção. Universidade Federal de Pernambuco, CAA, Programa de Pós-Graduação em Educação Contemporânea, 2018.

SOARES, Guilherme de Almeida. Para Alceu Moreira aposentados são vagabundos remunerados. Disponível em: http://www.esquerdadiario.com.br/Para-Alceu-Moreiraaposentados-sao-vagabundos-remunerados. Acessado em 30 de outubro de 2016.

SODRÉ, Nelson Werneck. Formação Econômica do Brasil. São Paulo: Brasiliense, 1967. STEDILE, João Pedro. [Org.]. A questão agrária no Brasil: o debate tradicional: 15001960. 1. ed. São Paulo: Expressão Popular, 2005.

STF. Ação Direta de Inconstitucionalidade 3239. Disponível em: http://www.stf.jus.br/arquivo/cms/noticiaNoticiaStf/anexo/ADI3239RW.pdf. Acessado em: 30 de outubro de 2016. 
STF. Ação Direta de Inconstitucionalidade 3239. Disponível em:

http://www.stf.jus.br/portal/cms/verNoticiaDetalhe.asp?idConteudo=369187. Acessado em 06 de março de 2020.

VINHAS, Moisés. Problema agrário-camponeses do Brasil - 1968. In: STEDILE, João Pedro.

[Org.]. A questão agrária no Brasil: o debate tradicional: 1500-1960. 1. ed. São Paulo:

Expressão Popular, 2005.

Submetido em: 10/03/2020

Aprovado em: 30/03/2020 